\title{
Anti-A $\beta$ Antibodies and Cerebral Amyloid Angiopathy Complications
}

\author{
Yannick Chantran ${ }^{1,2}$, Jean Capron ${ }^{1,3}$, Sonia Alamowitch ${ }^{1,3}$ and Pierre Aucouturier ${ }^{1,2 *}$ \\ ${ }^{1}$ Sorbonne Université, Inserm, UMRS 938, Hôpital St-Antoine, AP-HP, Paris, France, ${ }^{2}$ Département d'Immunologie \\ Biologique, Hôpital Saint-Antoine, AP-HP, Paris, France, ${ }^{3}$ Département de Neurologie, Hôpital Saint-Antoine, AP-HP, Paris, \\ France
}

OPEN ACCESS

Edited by:

Serge Nataf,

Université Claude Bernard

Lyon 1, France

Reviewed by:

Ana Lloret,

University of Valencia, Spain

Clara Ballerini,

University of Florence, Italy

*Correspondence:

Pierre Aucouturier

pierre.aucouturier@inserm.fr

Specialty section:

This article was submitted to

Multiple Sclerosis and

Neuroimmunology,

a section of the journa

Frontiers in Immunology

Received: 26 April 2019

Accepted: 19 June 2019

Published: 04 July 2019

Citation:

Chantran Y, Capron J, Alamowitch S and Aucouturier $P$ (2019) Anti-A $\beta$ Antibodies and Cerebral Amyloid Angiopathy Complications. Front. Immunol. 10:1534. doi: 10.3389/fimmu.2019.01534
Cerebral amyloid angiopathy (CAA) corresponds to the deposition of amyloid material in the cerebral vasculature, leading to structural modifications of blood vessel walls. The most frequent form of sporadic CAA involves fibrillar $\beta$-amyloid peptide (A $\beta$ ) deposits, mainly the 40 amino acid form $\left(A \beta_{1-40}\right)$, which are commonly found in the elderly with or without Alzheimer's disease. Sporadic CAA usually remains clinically silent. However, in some cases, acute complications either hemorrhagic or inflammatory can occur. Similar complications occurred after active or passive immunization against $A \beta$ in experimental animal models exhibiting CAA, and in subjects with Alzheimer's disease during clinical trials. The triggering of these adverse events by active immunization and monoclonal antibody administration in CAA-bearing individuals suggests that analogous mechanisms could be involved during spontaneous CAA complications, drawing particular attention to the role of anti-A $\beta$ antibodies. However, antibodies that react with several monomeric and aggregated forms of $A \beta$ spontaneously occur in virtually all human individuals, hence being part of the "natural antibody" repertoire. Natural antibodies are usually described as having low-affinity and high cross-reactivity toward microbial components and autoantigens. Although frequently of the IgM class, they also belong to $\lg G$ and IgA isotypes. They likely display homeostatic functions and protective roles in aging. Until recently, the peculiar properties of these natural antibodies have hindered proper analysis of the $A \beta$-reactive antibody repertoire and the study of their implication in CAA complications. Herein, we review and comment the evidences of an auto-immune nature of spontaneous CAA complications, and discuss implications for forthcoming research and clinical practice.

Keywords: cerebral amyloid angiopathy, autoimmunity, anti-A $\beta$ antibodies, immunotherapy, natural antibodies

\section{INTRODUCTION}

Adaptive immunity in neurodegenerative conditions has recently become of major interest in neurodegenerative conditions, especially in Alzheimer's disease (AD), because of its ability to modulate cerebral inflammation, and also following observations that immunotherapeutic approaches might impair pathological events. However, the nature of immune effectors and their mechanisms remain quite obscure. In this article we will focus mainly on antibodies that bind the $\beta$ amyloid peptide $(\mathrm{A} \beta)$, which has long been considered a key therapeutic target. Evident difficulties are due to the presence of blood anti-A $\beta$ antibodies in healthy and diseased individuals, implying that most quantitative studies provided little or no information on their pathological implication. 
Another key point is that effector functions of these antibodies frequently are suggested to result in complications of cerebral amyloid angiopathy (CAA).

\section{SPONTANEOUSLY OCCURRING ANTI-A $\beta$ ANTIBODIES IN HEALTH AND DISEASE}

\section{Natural Antibodies: Origin, Distinctive Properties and Functions}

Natural antibodies were defined as occurring in all normal individuals in the absence of overt antigenic stimulation (1). In spite of many controversies, it is now clear that natural antibodies represent a distinct entity that arises from separate Bcell lineages. Most natural antibodies are produced by a distinct $\mathrm{B}$-cell lineage termed B1 cells, but also in part by marginal zone $\mathrm{B}$ cells that belong to the conventional B2 lineage. B1 cells originate very early from precursors of the yolk sac and then from hematopoietic stem cells of the fetal liver, but they also differentiate from bone marrow precursors during the adult life (2).

Classical adaptive B-cell responses to T-dependent antigens feature germinal center reactions that include affinity maturation and isotype switching, resulting in high affinity specific antibodies of IgG, IgA and/or IgE classes. These mechanisms allow improvement of effector efficiency as a function of antigen exposure. At variance with classical antibodies, natural antibodies likely arise from processes that involve no or little B-T cell cooperation and affinity maturation, as suggested by frequent absence or paucity of somatic hypermutations and nucleotide $\mathrm{N}$-additions in the antibody variable regions. Thus, they display quite specific phenotypic properties as compared with conventional antibodies raised by immunization, including low binding affinities and multi-reactivity toward homologous antigens. Interestingly however, they may belong to IgG or IgA, as well as IgM classes $(1,3,4)$.

In relation with these peculiar properties, it is thought that natural antibodies display specific functions. They likely protect from infection at early stages of development. In addition to supposed protective roles in the newborn, the ongoing production of natural antibodies has been proposed to interfere with pathological events of adults, such as tumors, atherosclerosis, and neurodegenerative disorders in elderly (5).

Natural IgM antibodies have long been studied in both mice and humans. They display a variety of functions, including pathogen neutralization and killing, and clearance of apoptotic cells and debris that participate in preventing inflammation in several pathological contexts. They also participate in maturation of adaptive responses, especially through antigen recruitment in secondary lymphoid tissues. Other well-known examples of IgM natural antibodies are isohemagglutinins.

Natural IgG and IgA antibodies are also abundant in the blood and mucosal secretions, in spite of the supposed absence of $\mathrm{T}$ cell help. Like IgM natural antibodies, they seem to play protective roles, especially in partnership with lectins such as MannoseBinding Lectin and ficolins, against microbial pathogens and by controlling inflammation (3).
The repertoire of natural antibodies is clearly skewed, as they mostly recognize conserved self-structures $(6,7)$. Thus, they seem to undergo a selection process (8), suggesting physiological roles (9) including clearance of noxious molecules and cell debris, regulation of immune responses, and shaping of a primary repertoire that allows appropriate induced humoral responses. Numerous observations suggest that natural antibodies are protective against certain pathological conditions of aging, such as atherosclerosis, cancer and neurodegenerative disorders, and that the age-associated decreased expression of these antibodies could be responsible for proneness to these diseases (5). Indeed, circulating anti-alpha-synuclein antibody levels were found to be low in patients with Parkinson's disease (10). However, in AD, anti-Tau natural antibodies expression appears higher than in aged subjects (11). As discussed in the next section, the case of anti- $\mathrm{A} \beta$ antibodies and their expression in $\mathrm{AD}$ as compared to aged subjects remains controversial.

\section{Natural Anti-A $\beta$ Antibodies in Healthy Subjects, AD Patients and Related Conditions}

Natural antibodies that react with $\mathrm{A} \beta$ peptide have long been suggested by the finding of specific B-cells (12), and their invariable presence was confirmed by studies comparing $\mathrm{AD}$ patients and healthy subjects (see below). As also found for other natural autoantibodies, aging results in progressive decrease of circulating anti- $\mathrm{A} \beta$ levels (13). They belong to both $\operatorname{IgM}$ and $\operatorname{IgG}$ classes, and predominant IgG subclasses appear to be IgG1 and IgG3 in both healthy and diseased subjects (14). They display a large panel of specificities for both linear and conformational epitopes of the $A \beta$ molecules, oligomers, and fibrillar aggregates, and most interestingly, in vitro studies suggested that some natural anti- $A \beta$ antibodies could protect neurons from toxic $A \beta$ oligomers (15).

Analyses performed on serum or plasma from AD patients yielded remarkably incoherent results, as some of them revealed lower anti- $\mathrm{A} \beta$ antibody levels as compared with healthy controls (16-19), while others found higher levels in Alzheimer's disease patients (20-22) or no significant difference $(13,14,23)$. Analyses performed on cerebrospinal fluid (CSF) led to similar discrepancies, displaying either lower $(13,16)$ or higher $(20,22)$ levels of anti- $\mathrm{A} \beta$ antibody in $\mathrm{AD}$ patients as compared with healthy controls. A common observation of those studies was the striking heterogeneity of antibody titers in healthy as well as in diseased individuals.

A first explanation for inconsistent results may be the diversity of methods used for antibody analysis: coated reactive antigens were $A \beta_{1-40}(16,18,19)$ or $A \beta_{1-42}(13,17,21,23)$ in either oligomeric $(13,14,18)$, fibrillar $(20)$ or undefined isoforms $(16$, $17,19,21)$, at extremely variable concentrations; serum or plasma samples were tested either directly (17-20) or after dissociation of immune complexes $(13,14,21)$; revealed antibodies were either IgG only (19) or all immunoglobulin isotypes (23); finally, a variety of different quantitation formulas were used. The only methodological agreement between recent studies is the requirement of an initial immune complex dissociation step for 
a reliable analysis of anti-A $\beta$ antibodies $(13,14,21)$, using a mild acidic buffer in order to avoid artifacts (24). Indeed, a large part of circulating anti-A $\beta$ antibodies appears to be associated with a variety of undefined ligands, likely due to polyreactivity and the presence of anti-idiotypic antibodies (15). A possible additional bias is that IgM antibodies have been demonstrated to potentially block natural IgG reactivity (25).

In addition to methodological matters, the other explanations of differences in anti-A $\beta$ titers found between healthy and $\mathrm{AD}$ people relied on quite eclectic hypotheses: favored pathology due to decreasing antibody levels in aging (16), sequestering of antibodies by amyloid deposits (16), partial tolerization of B-cell responses (19) or decreased T-cell help (17), onset of an anti$\mathrm{A} \beta$ autoimmune reaction $(21,22)$, or failure of immune complex clearance (22).

\section{Natural Antibodies in Therapeutic Trials}

That age-related decline of natural autoantibodies favors the onset of pathological conditions related to antigenic targets is supported by strong arguments (3). The hypothesis that natural anti-A $\beta$ antibodies bear a strong protective potential $(13,26)$ has been the rationale for therapeutic trials in $\mathrm{AD}$ using human intravenous immunoglobulins (IVIg). Indeed, IVIg include natural antibodies to $\mathrm{A} \beta(27,28)$ as well as to protein Tau (29). IVIg infusions appeared to increase the levels of circulating anti-A $\beta$ (30), but while preliminary results on mild and moderate stages of $\mathrm{AD}$ had proven encouraging, more powerful trials failed to show a significant effect on cognitive decline (31-33). The reason of the lack of clinical efficacy of the natural anti$\mathrm{A} \beta$ antibodies contained in IVIg is a matter of debate. It has been shown that IgG levels were elevated in the CSF of treated subjects. Thus, anti-A $\beta$ antibodies penetrate into the CNS after infusion. Like other $A \beta$-modifying therapies, IVIg might be more effective in early stages of the disease. In addition, in these trials, IVIg were administered at low dose, similar to antibody replacement therapies. Immunomodulatory effects of IVIg are generally obtained in other neurological disease up to $2 \mathrm{~g} / \mathrm{kg}$ (33).

\section{ADAPTIVE IMMUNITY AGAINST A $\beta$ : THE AN1792 TRIAL}

Histological response and cognitive improvement after $A \beta$ vaccination in transgenic mouse models of $\mathrm{AD}$ have been received enthusiastically in the late 1990's $(34,35)$. Elan/WyethAyerst Pharmaceuticals set up the AN1792 trial in human (NCT00021723), the phase I study of safety and immunogenicity began in 1999, Dec., vaccinating mild-to-moderate AD subjects with pre-aggregated $\mathrm{A} \beta_{1-42}$ with adjuvant QS-21, and later on with QS-21 plus polysorbate- 80 0.4\%. After no major safety issue, phase IIa (Study 201) began in 2001, Oct., and was halted in 2002, Jan., when some patients presented with meningoencephalitis (36). Other adverse events other than meningoencephalitis occurred in the AN1792 study: two cases of encephalopathy including one without meningoencephalitis, two cases of convulsion, one thrombosis of the retina, one hemiplegia, and, interestingly, one case of intracerebral hemorrhage ( $\mathrm{ICH}$ ) related to CAA. However, confronted with the striking manifestations of brain inflammation, these post-immunization hemorrhagic or ischemic events have been overlooked (37).

Overall, 18 out of 300 (6\%) subjects treated with AN1792 in phase II developed meningoencephalitis, along with 1 subject from the extended phase I study (37-40). Clinically, these patients presented with subacute aseptic meningoencephalitis with confusion, lethargy, and headaches. Other symptoms were nausea, seizures, drowsiness, ataxia, aphasia, hemiparesia, with inconstant fever. As in aseptic meningoencephalitis, CSF analysis showed mild to moderate hyperlymphocytosis (3-130 cells $/ \mathrm{mm}^{3}$ ), often with mild hyperproteinorachia (39). Since none of the placebo-treated group developed such serious adverse events, it was obvious that these cases of meningoencephalitis related to the active immunization against $A \beta$.

Only 2 patients with post-A $\beta$ immunization meningoencephalitis were investigated at the histological level. The first patient (40) presented with fever, drowsiness, and unstable gait. At neuroimaging, MRI found white matter hyperintensities (WMH) and a more focal lesion, possibly associated with edema and inflammatory process. Post-mortem tissue sampling showed cortical areas without senile plaques, but still with CAA, and lymphocytic infiltration of leptomeningeal $A \beta$-laden blood vessels, or in perivascular space around cortical vessels, with sparse cellular infiltration of the parenchyma. Cellular infiltrates were mainly composed of CD4+ CD45RO+ T-cells, with few CD8+ T-cells, and without CD79a+ CD20+ B-cells. The second patient (41) presented similar plaquedevoid cortical areas and CD8+ T-cell-enriched perivascular lymphocytic infiltrates. In addition, the authors describe multiple macroscopic cortical hemorrhages that were not detected radiologically despite 3 MRI studies, and microscopic vasculopathy, namely lipohyalinosis. Interestingly, a third case (42) reported pathological findings in an AN1792-treated patient without clinical meningoencephalitis, which also presented perivascular cellular infiltrates in the leptomeningeal spaces, though to a lower extent as compared with the meningoencephalitis cases, and composed mainly of CD20+ B-cells and few CD3+ T-cells.

The immune mechanism, underlying these cases of meningoencephalitis has been debated, though it seemed obvious that adaptive immunity against $A \beta$ was at stake.

In the AN1792 trial, treated-patients were considered either antibody responder or non-responder with respect to the circulating anti-A $\beta$ antibody titer supposed to confer clinical benefit (38). While 20\% treated patients were considered antibody responders, most patients (at least 90\%) seemed to have produced detectable levels of circulating IgM and/or IgG anti-A $\beta$ after immunization (37). Among treated-patients with meningoencephalitis, 13 out of 18 belonged to the responder group, and 5 out of 18 to the non-responder group. Among these 5 non-responders, all of them had a measurable anti-A $\beta$ IgM response, and 4 a measurable anti-A $\beta$ IgG response in the blood (38).

If almost all treated patients developed an anti-A $\beta$ antibody response, one could question whether the antibody response was qualitatively different in patients with meningoencephalitis. 
However, it was shown by epitope-mapping that all immunized patients recognized a linear $\mathrm{B}$-cell epitope in the $\mathrm{N}$-terminus of the $A \beta$ peptide $\left(A \beta_{1-8}\right)$, independently of the occurrence of meningoencephalitis (43), and that their serum antibodies bound to parenchymal as well as vascular $A \beta$ aggregates, and not to cellular APP (44).

Out of 57 studied cases, 9 (15\%) had measurable CSF IgG or IgM anti-A $\beta$ antibody levels and 4 presented with meningoencephalitis (3 responders and 1 non-responder) (38). However, CSF antibodies from both patients with or without meningoencephalitis bound to senile plaques and vascular $A \beta$ aggregates (44).

T-cell responses during the AN1792 trial have been poorly studied. One paper reports on the higher occurrence of IFN $\gamma$ producing cells after $\mathrm{A} \beta_{1-42}$ stimulation in phase IIa treatedpatients as compared to phase I treated-patients, which was not significantly different from the placebo-treated group (45).

Confronted to the absence of noticeable differences in the anti-A $\beta$ antibody responses in AN1792-treated patients with and without meningoencephalitis, and considering the presence of lymphocytic infiltrates during such cases, it was assumed that the adaptive anti-A $\beta$ cellular T-cell response was detrimental when oriented toward cellular immunity through Th1 CD4+ and cytotoxic CD8+ T-cells, while anti-A $\beta$ B-cell response would remain innocuous and potentially beneficial for $\mathrm{AD}$ pathology. Thus, subsequent anti-A $\beta$ immunotherapy trials were based on anti-A $\beta$ antibodies either by selective "humoral" vaccines or, most frequently, by passive immunization using repeated humanized monoclonal antibody infusions, the complications of which have been linked to CAA.

\section{CEREBRAL AMYLOID ANGIOPATHY AND RELATED CLINICAL MANIFESTATIONS \\ Definition, Epidemiology, and Neuropathological Features of Cerebral Amyloid Angiopathy}

Deposited amyloid material in the blood vessel walls of the cerebral vasculature is made up of insoluble fibrils resulting from the polymerization of peptidic subunits with a "crossed $\beta$-sheet"-rich conformation. Mutations of several proteins have been described in familial forms of CAA, such as $A \beta$ precursor protein (APP) and other proteins (46). In addition to mutations, duplications of the wild-type $A P P$ gene are also associated with CAA, as found in Down syndrome and in autosomal dominant early onset Alzheimer's disease (47). Sporadic CAA, which is an $A \beta$-related disease without any mutation or duplication of the APP gene, represents the most common form of CAA and will be the main focus of this review.

The main risk factors of sporadic CAA are advancing age and the co-occurrence of $\operatorname{AD}(48,49)$. Both frequency and severity of CAA increase with age, affecting 35, 50, and 75\% of individuals in the 7th, 8th and 9th decades of life, respectively, regardless of CAA severity (49). Population-based studies show that in age-matched groups, demented individuals have higher risk to present CAA than non-demented individuals, regardless of CAA severity or considering solely severe CAA (50). Other genetic risk factors have been described, some of them overlapping with sporadic $\mathrm{AD}$ risk factors, making it difficult to distinguish which ones are independently related to sporadic CAA. The main genetic risk factor is ApoE polymorphism: the $\varepsilon 4$ allele is associated with the occurrence of $\mathrm{AD}$ and CAA, while the $\varepsilon 2$ allele appears protective against $\mathrm{AD}$ but associated with the risk of CAA-related intra-cerebral hemorrhage (ICH) (51). To explain these controversial findings, Greenberg et al. hypothesized that the APOE2 allele might be related to CAA vasculopathy but not vascular deposits, which they evidenced by showing that the APOE2 allele is more frequent in patients with grade 3-4 CAA (cracking of the vessel wall and paravascular leaking of blood) but that it is not over-represented in grade 2 CAA (complete amyloid replacement of vessels) (52). Hence, APOE4 might promote a higher risk of CAA-related hemorrhage by enhancing amyloid deposition, while APOE2 might cause amyloid-laden vessels to undergo vasculopathic changes that lead to their rupture.

It is indeed important to stress that, from a pathological point of view, CAA does not stand for the mere presence of fibrillary $\mathrm{A} \beta$ deposition in blood vessel walls. More severe vascular deposits are associated with vasculopathies, such as fibrinoid necrosis, thrombosis, microhemorrhages, or "doublebarreling," which is the concentric splitting of the vessel walls (53). Associated with smooth muscles cell degeneration and amyloid replacement of the whole vessel wall structure, these pathological features provide the histologic ground for clinical and paraclinical features of the manifestations of CAA. Cerebrovascular amyloid deposition in sporadic CAA involves the leptomeningeal and cortical medium- and small-sized arteries/arterioles, with or without involvement of the capillaries, and usually sparing the veins. The topography of CAA is not homogenous through the brain. The most affected areas being the occipital, parietal, frontal, then temporal lobes. In most advanced cases, other structures than the neocortex can be affected. It is now thought that some CAA features, such as capillary involvement, dyshoric angiopathy hence small vessel disease occurring by capillary occlusion, are associated with $\mathrm{AD}$ pathology, while leptomeningeal and arteriolar involvement is mainly independent from parenchymal amyloidosis of $\mathrm{AD}$ pathology (49). This could lead to a reappraisal of ApoE polymorphism in CAA: the $\varepsilon 4$ allele would be associated with $\mathrm{AD}$ capillary CAA, while the $\varepsilon 2$ allele would be associated with arterial CAA and its specific manifestations, such as lobar $\mathrm{ICH}(51)$.

\section{CAA Manifestations}

Cerebrovascular impairment in sporadic CAA may result in 3 subsets of manifestations: ischemia, bleeding, and inflammation (54).

Ischemic manifestations of CAA are cortical infarcts and WMH appearing on the MRI. They predominate in posterior regions of the brain where CAA accumulates, and relate to hypoperfusion or vessel occlusion (55-57).

Hemorrhagic manifestations of CAA are symptomatic ICH that differentiates from hypertensive $\mathrm{ICH}$ by strictly lobar localization, corresponding to the leptomeningeal and cortical 
topography of CAA (58). Besides symptomatic ICH, cortical microbleeds (59) and superficial cortical siderosis are other hemorrhagic features of CAA that can be displayed on MRI (60). Both ischemic and hemorrhagic features of CAA contribute to chronic vascular dementia.

Inflammatory manifestations of CAA involve a protean clinical presentation of corticosensitive encephalopathy, e.g., with subacute cognitive decline, seizures, headaches, and asymmetric T2 WMH. Histopathologicaly, different inflammatory subtypes have been described associated with CAA: (i) $\mathrm{A} \beta$-related angiitis, which corresponds to destructive transmural infiltrates with granulomatous features; (ii) CAA-related inflammation (CAA-ri), which corresponds to non-destructive perivascular lymphocytic infiltrates. However, besides histopathological phenotypes, clinical features, imaging and outcome largely overlap, making these entities likely part of the same spectrum $(61,62)$. These pathologies represent up to $30 \%$ of primary CNS vasculitis, making it part of single-organ vasculitis in the Chappell-Hill revised nomenclature $(63,64)$, and introducing the hypothesis of an auto-immune mechanism of these manifestations.

With the noticeable exception of extremely rare CAAri cases, the potential auto-immune mechanisms at stake in CAA manifestations have been neglected. Clinical and imaging features of CAA-related hemorrhages or ischemia have been conceived as the consequence of mechanical constrains, blood wall weakening, mural degeneration and or vessel occlusion related to vascular $A \beta$ deposition.

However, it has been convincingly shown that CAA was increased in patients immunized with AN1792. In a post-mortem study of 9 treated-patients, Boche et al. found a worsening of CAA in AN1792 patients, with cerebrovascular deposits containing not only $A \beta_{1-40}$, which is classically found in CAA, but also higher cerebrovascular levels of $A \beta_{1-42}$, the main component of senile plaques. These patients also had a higher rate of vasculopathies and microhemorrhages (65). In our opinion, and as suggested by some authors $(66,67)$, the possibility cannot be discarded that detrimental adaptive immunity raised against $A \beta$ during the AN1792, whether humoral or cellular, was as least partly related to cerebrovascular deposits, given: (i) the predominant leptomeningeal and perivascular location of cellular infiltrates in meningoencephalitis cases during the AN1792 trial, (ii) the occurrence of some post-immunization hemorrhagic or ischemic severe adverse events, including one case of CAA-related ICH, and (iii) the multiple cortical hemorrhages and associated lipohyalinosis described by Ferrer et al. in one meningoencephalitis case (41).

Whether meningoencephalitis and other adverse events were related to adaptive immune reaction against parenchymal or against vascular $A \beta$ deposits, it was assumed that T-cell anti$\mathrm{A} \beta$ response was detrimental, while humoral adaptive anti- $\mathrm{A} \beta$ response was thought to be inocuous and potentially beneficial. However, adverse events also occurred in the course of passive immunotherapies with anti-A $\beta$ antibodies, which shed a new light on the pathophysiology of induced and spontaneouslyoccurring CAA manifestations.

\section{MONOCLONAL ANTI-A $\beta$ ANTIBODIES AND THEIR RELATIONSHIP TO CAA MANIFESTATIONS}

\section{The Illustrative Case of Bapineuzumab}

Bapineuzumab is a monoclonal humanized IgG1 antibody corresponding to the murine clone 3D6, targeting the $\mathrm{N}$ terminus of the $A \beta$ peptide $\left(A \beta_{1-5}\right)$. However, unlike circulating antibodies arising in AN1792 patients, Bapineuzumab does not recognize a linear epitope but a conformational one (68). While patients treated by Bapineuzumab showed a decrease of the cerebral amyloid load by $11 \mathrm{C}$-PiB TEP-scan $(69,70)$, they did not show clinical improvement (71).

During the phase I trial, 3 out of 10 patients treated with a single infusion of the highest dose of Bapineuzumab (5 $\mathrm{mg} / \mathrm{kg}$ ) developed transient signal abnormalities on $\mathrm{T} 2 * /$ fluid attenuation inversion recovery (FLAIR) sequences, interpreted as a sign of vasogenic cerebral edema (72). Additional cases were reported during phase II (73) and phase III (74). First referred as vasogenic edema, these amyloid-related imaging abnormalities (ARIA) were included in a spectrum of so-called ARIA-E (E standing for effusion), that encompasses increased MR signal intensity on FLAIR or other T2-weighted sequences in the parenchyma gray or white matter and/or leptomeninges, sometimes in the cerebellum or brainstem. Interestingly, this radiological presentation appears similar to MRI presentation of spontaneous inflammatory manifestations of CAA $(66,74)$. ARIA-E was found in 17\% (36/210) Bapineuzumab-treated subjects, appearing after the first or second infusion, in a dose-dependent manner, with an increased risk in ApoE $\varepsilon 4$ carriers (7\% among non-carriers, 18\% among heterozygous, $36 \%$ among homozygous) (71). ARIA-E was associated with clinical manifestations during Bapineuzumab trials in about $20 \%$ subjects. If acute clinical worsening prompted off-protocol MRI in some cases, most patients were detected by per-protocol MRI. However, some were retrospectively found to present clinical signs, similar to inflammatory manifestations of CAA. Another type of ARIA, namely ARIA-H ( $\mathrm{H}$ standing for hemorrhages) appeared during the Bapineuzumab studies in $12 \%$ patients, and featured either microbleeds or cortical superficial siderosis similar to spontaneous hemorrhagic manifestations of CAA. ARIA-E and ARIA-H are not independent phenomena. First, the presence of baseline microbleeds increased the risk of ARIAE. Second, de novo ARIA-H were 10 times more prevalent in patients with ARIA-E (67). They appeared during the same timeline, and often in the same cortical areas (66).

Although no neuropathological description of ARIA-E have been reported, the pathophysiological relationship between ARIA-E and spontaneous CAA-related inflammation on the one hand, and ARIA-H, and spontaneous CAA-related hemorrhages on the other hand, was suggested. Hence, it became obvious that antibodies targeting $A \beta$ are sufficient to trigger CAA-like manifestations, and that $\mathrm{T}$-cell anti-A $\beta$ responses arising from active immunization are not required. Thus, some authors suggested that despite differences in severity, meningoencephalitis and ARIA-E could be part of 
a same pathophysiological spectrum linked to $A \beta$ vascular deposition $(66,67)$.

\section{ARIA in Other Anti-A $\beta$ Passive Immunotherapies}

Aducanumab is a human IgG1 selected from a B-cell library obtained from healthy aged donors who were cognitively normal. It was selected for its reactivity against soluble $A \beta$ oligomers and insoluble $A \beta$ fibrils. Similarly to Bapineuzumab, $22 \%$ (27/125) Aducanumab-treated subjects developed ARIA-E, 33\% being symptomatic, usually mild. Once again, this phenomenon appeared to be dose-dependent and ApoE \&4-related. Among ARIA-E subjects, 15 (56\%) also had ARIA-H. In particular, while none of the placebo-treated subjects had cortical superficial siderosis, 9 Aducanumab-treated patients presented with such manifestations (75).

Gantenerumab is a human IgG1 selected by phage display from a human antibody library and optimized in vitro to enhance its affinity to fibrillar $A \beta$, and binds to the $\mathrm{N}$-terminal $\mathrm{A} \beta_{1-10}$ but also the middle portion $A \beta_{19-26}$ (76). Then again, 10\% (53/531) treated patients developed ARIA-E, and 20\% (104/531) developed ARIA-H in a dosedependent, ApoE ع4-related manner. The clinical course was similar to those of Bapineuzumab and Aducanumab in terms of incidence, symptoms, kinetics and response to withdrawal (77).

Solanezumab is a humanized IgG1 that binds to the middomain of soluble A $\beta$. ARIA-E occurred in 18 Solanezumabtreated subjects, however it was always asymptomatic, with a low incidence (1.1\%), and without statistical difference from placebo-treated subjects $(0.5 \%)$. Under Solanezumab treatment, ARIA-H was more frequent than ARIA-E (9.1\%), but once again without statistically significant difference from placebo-treated subjects (7.3\%). Even though Solanezumab did not seem to induce a higher frequency of ARIA, the link between ARIAE and ARIA-H was still obvious: $71 \%$ of patients with ARIA-E displayed increases in ARIA- $\mathrm{H}$ at the time of ARIA-E, and $48 \%$ had co-localized ARIA-H and ARIA-E (78).

Crenezumab is a humanized IgG4 that was designed in order to avoid Fc $\gamma$ Rc-binding, hence anti- $\mathrm{A} \beta$ antibodymediated cellular reaction in order to lower the risk of ARIA. Crenezumab has a preferential affinity for soluble oligomers (79). Crenezumab-treated patients in the ABBY study did not show a higher incidence of ARIA-E, microbleeds and cortical superficial siderosis. Of note, one asymptomatic macrohemorrhage was reported in a treated-patient (80). In the independent BLAZE study, however, $14.5 \%$ treated-patients presented new ARIA-H, as compared to $3.4 \%$ placebo-treated patients (81).

Ponezumab is a humanized IgG2 targeting the C-terminus of $A \beta_{30-40}$ that binds to soluble $A \beta$. The incidence of microhemorrhages was $16.4 \%$ in the Ponezumab group and $21.4 \%$ in the placebo group. However, various MRI features corresponding to what can be observed during CAA were reported solely in the Ponezumab-treated group, either inflammatory-like (1 case with ARIA-E associated with superficial siderosis, 1 case with cerebral/meningeal enhancement), hemorrhagic-like (1 case of subdural hematoma), or ischemic-like (4 cases of cortical infarcts, 2 subcortical gray-matter infarcts) (82). In $24 \mathrm{CAA}$ patients treated with Ponezumab, 2 hemorrhagic adverse events (1 case of cerebral hemorrhage, 1 case of subdural hematoma), and 1 inflammatorylike event ( 1 case of asymptomatic ARIA-E) occurred but were not considered treatment-related by the investigators (83).

Other antibodies have been used in $\mathrm{A} \beta$-related diseases. $\mathrm{AAB}$ 003 was developed by introducing a 3 -aminoacid mutation in the $\mathrm{Fc}$ region of Bapineuzumab, resulting in reduced $\mathrm{Fc} \gamma \mathrm{Rc}$ binding and reduced binding to C1q. ARIA-H and ARIA-E were however reported in the treated group (84). BAN2401 is a humanized IgG1 monoclonal antibody that selectively binds to $A \beta$ soluble protofibrils and that did not appear to be related with ARIA during phase I (85).

\section{CONCLUSION: IMPLICATIONS FOR THE MANAGEMENT OF CAA COMPLICATIONS}

Overall, treatments of $\mathrm{A} \beta$-related diseases with monoclonal anti- $\mathrm{A} \beta$ antibodies can trigger CAA-like manifestations, either inflammatory or hemorrhagic. In most cases, these radiological signs are not associated with clinical manifestations. Since they were followed by treatment discontinuation in most trials, the question of whether the asymptomatic radiological signs would have remained infra-clinical or represent a pre-clinical state remains unanswered. The mechanism of such CAA-like manifestations is also unknown. Anti- $A \beta$ antibodies could simply worsen CAA (65) by displacing parenchymal $\mathrm{A} \beta$ to the cerebral vasculature, hence enhancing the risk of CAA manifestations. A more direct pathogenic role for anti- $A \beta$ antibodies would involve the mediation of inflammation and/or the triggering of hemorrhagic events after antibody binding to cerebrovascular deposits, by impairment of the structural integrity of the blood vessel, complement-mediated or $\mathrm{Fc} \gamma \mathrm{Rc}$-mediated inflammation. As a general rule, three concomitant factors seem to modulate the risk of ARIA. The dose-dependent effect of such anti$A \beta$ monoclonal antibodies is the first and better established one. The second one is anti-A $\beta$ antibody isotype: IgG1 anti$\mathrm{A} \beta$ monoclonal antibodies such as Bapineuzumab, Aducanumab, and Gantenerumab, triggered ARIA-E and ARIA-H, while IgG2 (Ponezumab) and $\operatorname{IgG} 4$ (Crenezumab) appeared less prone to trigger CAA-like manifestations. The third one is the selectivity for soluble or deposited forms of $A \beta$ : Ponezumab and Crenezumab were more selective for targeting soluble forms of A $\beta$, as were Solanezumab and BAN2401, hence maybe less prone than other antibodies to bind to cerebrovascular deposits in body fluids.

In any case, the pathogenicity of anti- $\mathrm{A} \beta$ antibodies likely depends on their characteristics: isotype (Ig class and subclass), specificity toward soluble or aggregated forms of $A \beta_{1-42}$ or $\mathrm{A} \beta_{1-40}$, differential affinity for such forms, and concentration in body fluids.

By analogy with passive immunotherapy-induced ARIA, these considerations lead to the hypothesis that in sporadic CAA, the occurrence of some species of anti-A $\beta$ antibodies can trigger spontaneous inflammatory or hemorrhagic CAA manifestations. However, serum anti-A $\beta$ antibodies have been scarcely studied in 
CAA (86). Most investigations focused on (i) CSF antibodies (ii) during CAA-related inflammation. Piazza et al. showed elevated CSF levels of anti-A $\beta$ IgG during the clinical and radiological active phase of spontaneous CAA-ri (87). The same group argued in favor of an intrathecal synthesis of CSF anti-A $\beta$ antibodies, based on a single case (88). However, experimental evidence in transgenic mouse model that exhibit $\mathrm{AD}$-like pathology with a strong CAA component suggested that blood anti-A $\beta$ antibodies are by themselves prone to aggravate CAA and related manifestations, including hemorrhages $(89,90)$.

Anti-A $\beta$ antibodies circulating in the serum are part of the natural antibody repertoire. Despite methodological difficulties hindering their study, adverse events that occurred during anti- $\mathrm{A} \beta$ immunotherapies in $\mathrm{AD}$ suggest that natural anti- $\mathrm{A} \beta$ antibodies are likely to play a role in the triggering of CAArelated inflammation, but also in other CAA manifestations such as hemorrhagic features. Whether such pathogenic anti$\mathrm{A} \beta$ species would be part of an individual pre-immune natural repertoire, or would be the result of adaptive processes driven by cerebrovascular deposits during the course of CAA is unknown. The pathogenic features of these anti-A $\beta$ antibodies that would correlate with CAA clinical phenotypes remain to be determined by a fine-scale analysis of the circulating anti-A $\beta$ antibody repertoire, focusing on serum concentration,

\section{REFERENCES}

1. Coutinho A, Kazatchkine MD, Avrameas S. Natural autoantibodies. Curr Opin Immunol. (1995) 7:812-8. doi: 10.1016/0952-7915(95)80053-0

2. Montecino-Rodriguez E, Dorshkind K. B-1 B cell development in the fetus and adult. Immunity. (2012) 36:13-21. doi: 10.1016/j.immuni.2011.11.017

3. Panda S, Ding JL. Natural antibodies bridge innate and adaptive immunity. $J$ Immunol. (2015) 194:13-20. doi: 10.4049/jimmunol.1400844

4. Baccala R, Quang TV, Gilbert M, Ternynck T, Avrameas S. Two murine natural polyreactive autoantibodies are encoded by nonmutated germ-line genes. Proc Natl Acad Sci USA. (1989) 86:4624-8. doi: 10.1073/pnas.86.12.4624

5. Rothstein TL. Natural antibodies as rheostats for susceptibility to chronic diseases in the aged. Front Immunol. (2016) 7:127. doi: 10.3389/fimmu.2016.00127

6. Mouthon L, Nobrega A, Nicolas N, Kaveri SV, Barreau C, Coutinho $\mathrm{A}$, et al. Invariance and restriction toward a limited set of self-antigens characterize neonatal IgM antibody repertoires and prevail in autoreactive repertoires of healthy adults. Proc Natl Acad Sci USA. (1995) 92:383943. doi: 10.1073/pnas.92.9.3839

7. Mouthon L, Haury M, Lacroix-Desmazes S, Barreau C, Coutinho A, Kazatchkine MD. Analysis of the normal human IgG antibody repertoire. Evidence that IgG autoantibodies of healthy adults recognize a limited and conserved set of protein antigens in homologous tissues. I Immunol. (1995) 154:5769-78.

8. Hardy RR, Hayakawa K. Selection of natural autoreactive B cells. Clin Exp Rheumatol. (2015) 33(4 suppl. 92):S80-6.

9. Nagele EP, Han M, Acharya NK, DeMarshall C, Kosciuk MC, Nagele RG. Natural IgG autoantibodies are abundant and ubiquitous in human sera, and their number is influenced by age, gender, and disease. PLoS ONE. (2013) 8:e60726. doi: 10.1371/journal.pone.0060726

10. Besong-Agbo D, Wolf E, Jessen F, Oechsner M, Hametner E, Poewe W, et al. Naturally occurring $\alpha$-synuclein autoantibody levels are lower in patients with Parkinson disease. Neurology. (2013) 80:169-75. doi: 10.1212/WNL.0b013e31827b90d1

11. Rosenmann H, Meiner Z, Geylis V, Abramsky O, Steinitz M. Detection of circulating antibodies against tau protein in its unphosphorylated isotypes and IgG subclasses, specificity, and affinity toward soluble or aggregated forms of $A \beta$. Such analysis would deliver pathophysiological insights about CAA manifestations, but would hopefully provide new biomarkers for the prediction of spontaneous and immunotherapy-induced complications in sporadic CAA and AD.

To date, cognition and education remain the best predictors of dementia in the elderly, while ApoE polymorphisms consistently predict $A \beta$-related pathology (91). The vascular component in $\mathrm{AD}$ and other dementia has raised more and more interest over the last years. In this view, the study of spontaneously produced pathogenic anti-A $\beta$ antibodies seems promising. Its inclusion in prediction models of dementia might be the keystone that would link cerebrovascular $\mathrm{A} \beta$ deposition and macro- or microvascular impairment.

\section{AUTHOR CONTRIBUTIONS}

YC and PA wrote the manuscript. All authors revised the manuscript.

\section{ACKNOWLEDGMENTS}

The authors thank the SATT Lutech for its support.

and in its neurofibrillary tangles-related phosphorylated state in Alzheimer's disease and healthy subjects. Neurosci Lett. (2006) 410:90-3. doi: 10.1016/j.neulet.2006.01.072

12. Gaskin F, Finley J, Fang Q, Xu S, Fu SM. Human antibodies reactive with beta-amyloid protein in Alzheimer's disease. J Exp Med. (1993) 177:11816. doi: 10.1084/jem.177.4.1181

13. Britschgi M, Olin CE, Johns HT, Takeda-Uchimura Y, LeMieux MC, Rufibach $\mathrm{K}$, et al. Neuroprotective natural antibodies to assemblies of amyloidogenic peptides decrease with normal aging and advancing Alzheimer's disease. Proc Natl Acad Sci USA. (2009) 106:12145-50. doi: 10.1073/pnas.0904866106

14. Dorothée G, Bottlaender M, Moukari E, de Souza LC, Maroy $\mathrm{R}$, Corlier F, et al. Distinct patterns of antiamyloid- $\beta$ antibodies in typical and atypical Alzheimer disease. Arch Neurol. (2012) 69:1181-5. doi: 10.1001/archneurol.2012.604

15. Szabo P, Relkin N, Weksler ME. Natural human antibodies to amyloid beta peptide. Autoimmun Rev. (2008) 7:415-20. doi: 10.1016/j.autrev.2008.03.007

16. Du Y, Dodel R, Hampel H, Buerger K, Lin S, Eastwood B, et al. Reduced levels of amyloid beta-peptide antibody in Alzheimer disease. Neurology. (2001) 57:801-5. doi: 10.1212/WNL.57.5.801

17. Weksler ME, Relkin N, Turkenich R, LaRusse S, Zhou L, Szabo P. Patients with Alzheimer disease have lower levels of serum anti-amyloid peptide antibodies than healthy elderly individuals. Exp Gerontol. (2002) 37:9438. doi: 10.1016/S0531-5565(02)00029-3

18. Moir RD, Tseitlin KA, Soscia S, Hyman BT, Irizarry MC, Tanzi RE. Autoantibodies to redox-modified oligomeric Abeta are attenuated in the plasma of Alzheimer's disease patients. J Biol Chem. (2005) 280:1745863. doi: 10.1074/jbc.M414176200

19. Jianping L, Zhibing Y, Wei Q, Zhikai C, Jie X, Jinbiao L. Low avidity and level of serum anti-Abeta antibodies in Alzheimer disease. Alzheimer Dis Assoc Disord. (2006) 20:127-32. doi: 10.1097/00002093-200607000-00001

20. Nath A, Hall E, Tuzova M, Dobbs M, Jons M, Anderson C, et al. Autoantibodies to amyloid $B$-peptide $(A B)$ are increased in Alzheimer's disease patients and $A B$ antibodies can enhance $A B$ neurotoxicity: implications for disease pathogenesis and vaccine development. Neuromolecular Med. (2003) 3:29-39 doi: 10.1385/NMM: $3: 1: 29$ 
21. Storace D, Cammarata S, Borghi R, Sanguineti R, Giliberto L, Piccini A, et al. Elevation of \{beta\} amyloid 1-42 autoantibodies in the blood of amnestic patients with mild cognitive impairment. Arch Neurol. (2010) 67:867-72. doi: 10.1001/archneurol.2010.137

22. Maftei M, Thurm F, Schnack C, Tumani H, Otto M, Elbert T, et al. Increased levels of antigen-bound $\beta$-amyloid autoantibodies in serum and cerebrospinal fluid of Alzheimer's disease patients. PLoS ONE. (2013) 8:e68996. doi: 10.1371/journal.pone.0068996

23. Hyman BT, Smith C, Buldyrev I, Whelan C, Brown H, Tang MX, et al. Autoantibodies to amyloid-beta and Alzheimer's disease. Ann Neurol. (2001) 49:808-10. doi: 10.1002/ana.1061

24. $\mathrm{Li} \mathrm{Q}$, Gordon $\mathrm{M}$, Cao $\mathrm{C}$, Ugen KE, Morgan D. Improvement of a low $\mathrm{pH}$ antigen-antibody dissociation procedure for ELISA measurement of circulating anti-Abeta antibodies. BMC Neurosci. (2007) 8:22. doi: 10.1186/1471-2202-8-22

25. Adib M, Ragimbeau J, Avrameas S, Ternynck T. IgG autoantibody activity in normal mouse serum is controlled by IgM. J Immunol. (1990) 145:3807-13.

26. Kellner A, Matschke J, Bernreuther C, Moch H, Ferrer I, Glatzel M. Autoantibodies against beta-amyloid are common in Alzheimer's disease and help control plaque burden. Ann Neurol. (2009) 65:2431. doi: 10.1002/ana.21475

27. Dodel R, Hampel H, Depboylu C, Lin S, Gao F, Schock S, et al. Human antibodies against amyloid beta peptide: a potential treatment for Alzheimer's disease. Ann Neurol. (2002) 52:253-6. doi: 10.1002/ana.10253

28. O'Nuallain B, Hrncic R, Wall JS, Weiss DT, Solomon A. Diagnostic and therapeutic potential of amyloid-reactive IgG antibodies contained in human sera. J Immunol. (2006) 176:7071-8. doi: 10.4049/jimmunol.176.11.7071

29. Hromadkova L, Kolarova M, Jankovicova B, Bartos A, Ricny J, Bilkova Z, et al. Identification and characterization of natural antibodies against tau protein in an intravenous immunoglobulin product. J Neuroimmunol. (2015) 289:121-9. doi: 10.1016/j.jneuroim.2015.10.017

30. Relkin NR, Szabo P, Adamiak B, Burgut T, Monthe C, Lent RW, et al. 18-Month study of intravenous immunoglobulin for treatment of mild Alzheimer disease. Neurobiol Aging. (2009) 30:1728-36. doi: 10.1016/j.neurobiolaging.2007.12.021

31. Dodel R, Rominger A, Bartenstein P, Barkhof F, Blennow K, Förster $\mathrm{S}$, et al. Intravenous immunoglobulin for treatment of mild-tomoderate Alzheimer's disease: a phase 2, randomised, doubleblind, placebo-controlled, dose-finding trial. Lancet Neurol. (2013) 12:233-43. doi: 10.1016/S1474-4422(13)70014-0

32. Kile S, Au W, Parise C, Rose K, Donnel T, Hankins A, et al. IVIG treatment of mild cognitive impairment due to Alzheimer's disease: a randomised double-blinded exploratory study of the effect on brain atrophy, cognition and conversion to dementia. J Neurol Neurosurg Psychiatry. (2017) 88:106112. doi: 10.1136/jnnp-2015-311486

33. Relkin NR, Thomas RG, Rissman RA, Brewer JB, Rafii MS, van Dyck CH, et al. A phase 3 trial of IV immunoglobulin for Alzheimer disease. Neurology. (2017) 88:1768-75. doi: 10.1212/WNL.0000000000003904

34. Schenk D, Barbour R, Dunn W, Gordon G, Grajeda H, Guido T, et al. Immunization with amyloid-beta attenuates Alzheimer-disease-like pathology in the PDAPP mouse. Nature. (1999) 400:173-7. doi: 10.1038/22124

35. Morgan D, Diamond DM, Gottschall PE, Ugen KE, Dickey C, Hardy J, et al. A beta peptide vaccination prevents memory loss in an animal model of Alzheimer's disease. Nature. (2000) 408:982-5. doi: 10.1038/35050116

36. Check E. Nerve inflammation halts trial for Alzheimer's drug. Nature. (2002) 415:462. doi: 10.1038/415462a

37. Bayer AJ, Bullock R, Jones RW, Wilkinson D, Paterson KR, Jenkins L, et al. Evaluation of the safety and immunogenicity of synthetic Abeta42 (AN1792) in patients with AD. Neurology. (2005) 64:94-101. doi: 10.1212/01.WNL.0000148604.77591.67

38. Gilman S, Koller M, Black RS, Jenkins L, Griffith SG, Fox NC, et al. Clinical effects of Abeta immunization (AN1792) in patients with $\mathrm{AD}$ in an interrupted trial. Neurology. (2005) 64:1553-62. doi: 10.1212/01.WNL.0000159740.16984.3C

39. Orgogozo JM, Gilman S, Dartigues JF, Laurent B, Puel M, Kirby LC, et al. Subacute meningoencephalitis in a subset of patients with AD after Abeta42 immunization. Neurology. (2003) 61:46-54. doi: 10.1212/01.WNL.0000073623.84147.A8
40. Nicoll JA, Wilkinson D, Holmes C, Steart P, Markham H, Weller RO. Neuropathology of human Alzheimer disease after immunization with amyloid-beta peptide: a case report. Nat Med. (2003) 9:44852. doi: $10.1038 / \mathrm{nm} 840$

41. Ferrer I, Boada Rovira M, Sánchez Guerra ML, Rey MJ, Costa-Jussá F. Neuropathology and pathogenesis of encephalitis following amyloidbeta immunization in Alzheimer's disease. Brain Pathol. (2004) 14:1120. doi: 10.1111/j.1750-3639.2004.tb00493.x

42. Masliah E, Hansen L, Adame A, Crews L, Bard F, Lee C, et al. Abeta vaccination effects on plaque pathology in the absence of encephalitis in Alzheimer disease. Neurology. (2005) 64:129-31. doi: 10.1212/01.WNL.0000148590.39911.DF

43. Lee M, Bard F, Johnson-Wood K, Lee C, Hu K, Griffith SG, et al. Abeta42 immunization in Alzheimer's disease generates Abeta $\mathrm{N}$-terminal antibodies. Ann Neurol. (2005) 58:430-5. doi: 10.1002/ana.20592

44. Hock C, Konietzko U, Papassotiropoulos A, Wollmer A, Streffer J, von Rotz RC, et al. Generation of antibodies specific for beta-amyloid by vaccination of patients with Alzheimer disease. Nat Med. (2002) 8:12705. doi: $10.1038 / \mathrm{nm} 783$

45. Pride M, Seubert P, Grundman M, Hagen M, Eldridge J, Black RS. Progress in the active immunotherapeutic approach to Alzheimer's disease: clinical investigations into AN1792-associated meningoencephalitis. Neurodegener Dis. (2008) 5:194-6. doi: 10.1159/000113700

46. Revesz T, Holton JL, Lashley T, Plant G, Frangione B, Rostagno $A$, et al. Genetics and molecular pathogenesis of sporadic and hereditary cerebral amyloid angiopathies. Acta Neuropathol. (2009) 118:115-30. doi: 10.1007/s00401-009-0501-8

47. Cabrejo L, Guyant-Maréchal L, Laquerrière A, Vercelletto M, De la Fournière F, Thomas-Antérion C, et al. Phenotype associated with APP duplication in five families. Brain. (2006) 129:2966-76. doi: 10.1093/brain/awl237

48. Vinters HV, Gilbert JJ. Cerebral amyloid angiopathy: incidence and complications in the aging brain. II. The distribution of amyloid vascular changes. Stroke. (1983) 14:924-8. doi: 10.1161/01.STR.14.6.924

49. Thal DR, Griffin WS, de Vos RA, Ghebremedhin E. Cerebral amyloid angiopathy and its relationship to Alzheimer's disease. Acta Neuropathol. (2008) 115:599-609. doi: 10.1007/s00401-008-0366-2

50. Keage HA, Carare RO, Friedland RP, Ince PG, Love S, Nicoll JA, et al. Population studies of sporadic cerebral amyloid angiopathy and dementia: a systematic review. BMC Neurol. (2009) 9:3. doi: 10.1186/1471-2377-9-3

51. Yamada M. Cerebral amyloid angiopathy: emerging concepts. J Stroke. (2015) 17:17-30. doi: 10.5853/jos.2015.17.1.17

52. Greenberg SM, Vonsattel JP, Segal AZ, Chiu RI, Clatworthy AE, Liao A, et al. Association of apolipoprotein E epsilon2 and vasculopathy in cerebral amyloid angiopathy. Neurology. (1998) 50:961-5. doi: 10.1212/WNL.50.4.961

53. Love $\mathrm{S}$, Chalmers $\mathrm{K}$, Ince $\mathrm{P}$, Esiri $\mathrm{M}$, Attems $\mathrm{J}$, Jellinger $\mathrm{K}$, et al. Development, appraisal, validation and implementation of a consensus protocol for the assessment of cerebral amyloid angiopathy in post-mortem brain tissue. Am J Neurodegener Dis. (2014) 3:19-32.

54. Charidimou A, Boulouis G, Gurol ME, Ayata C, Bacskai BJ, Frosch MP, et al. Emerging concepts in sporadic cerebral amyloid angiopathy. Brain. (2017) 140:1829-50. doi: 10.1093/brain/awx047

55. Zhu YC, Chabriat H, Godin O, Dufouil C, Rosand J, Greenberg SM, et al. Distribution of white matter hyperintensity in cerebral hemorrhage and healthy aging. J Neurol. (2012) 259:530-6. doi: 10.1007/s00415-011-6218-3

56. Thanprasertsuk S, Martinez-Ramirez S, Pontes-Neto OM, Ni J, Ayres A, Reed A, et al. Posterior white matter disease distribution as a predictor of amyloid angiopathy. Neurology. (2014) 83:794-800. doi: 10.1212/WNL.0000000000000732

57. Gurol ME, Viswanathan A, Gidicsin C, Hedden T, Martinez-Ramirez S, Dumas A, et al. Cerebral amyloid angiopathy burden associated with leukoaraiosis: a positron emission tomography/magnetic resonance imaging study. Ann Neurol. (2013) 73:529-36. doi: 10.1002/ana.23830

58. Hirohata M, Yoshita M, Ishida C, Ikeda SI, Tamaoka A, Kuzuhara S, et al. Clinical features of non-hypertensive lobar intracerebral hemorrhage related to cerebral amyloid angiopathy. Eur J Neurol. (2010) 17:8239. doi: 10.1111/j.1468-1331.2009.02940.x

59. Cordonnier C, Al-Shahi Salman R, Wardlaw J. Spontaneous brain microbleeds: systematic review, subgroup analyses and standards for 
study design and reporting. Brain. (2007) 130:1988-2003. doi: 10.1093/ brain/awl387

60. Linn J, Halpin A, Demaerel P, Ruhland J, Giese AD, Dichgans $M$, et al. Prevalence of superficial siderosis in patients with cerebral amyloid angiopathy. Neurology. (2010) 74:134650. doi: 10.1212/WNL.0b013e3181dad605

61. Salvarani C, Hunder GG, Morris JM, Brown RD Jr, Christianson T, Giannini C. A $\beta$-related angiitis: comparison with CAA without inflammation and primary CNS vasculitis. Neurology. (2013) 81:1596603. doi: 10.1212/WNL.0b013e3182a9f545

62. Salvarani C, Brown RD Jr, Christianson T, Miller DV, Giannini C, Huston J III, et al. An update of the Mayo Clinic cohort of patients with adult primary central nervous system vasculitis: description of 163 patients. Medicine. (2015) 94:e738. doi: 10.1097/MD.0000000000000738

63. Jennette JC, Falk RJ, Bacon PA, Basu N, Cid MC, Ferrario F, et al. 2012 revised International Chapel Hill Consensus Conference Nomenclature of Vasculitides. Arthritis Rheum. (2013) 65:1-11. doi: 10.1002/art.37715

64. Salvarani C, Brown RD Jr, Hunder GG. Adult primary central nervous system vasculitis. Lancet. (2012) 380:767-77. doi: 10.1016/S0140-6736(12)60069-5

65. Boche D, Zotova E, Weller RO, Love S, Neal JW, Pickering RM, et al. Consequence of Abeta immunization on the vasculature of human Alzheimer's disease brain. Brain. (2008) 131:3299310. doi: 10.1093/brain/awn261

66. Sperling RA, Jack CR Jr, Black SE, Frosch MP, Greenberg SM, Hyman BT, et al. Amyloid-related imaging abnormalities in amyloid-modifying therapeutic trials: recommendations from the Alzheimer's Association Research Roundtable Workgroup. Alzheimers Dement. (2011) 7:36785. doi: 10.1016/j.jalz.2011.05.2351

67. Frisoni GB. ARIA from off-key operas? Lancet Neurol. (2012) 11:2078. doi: 10.1016/S1474-4422(12)70021-2

68. Miles LA, Crespi GA, Doughty L, Parker MW. Bapineuzumab captures the $\mathrm{N}$-terminus of the Alzheimer's disease amyloid-beta peptide in a helical conformation. Sci Rep. (2013) 3:1302. doi: 10.1038/srep01302

69. Rinne JO, Brooks DJ, Rossor MN, Fox NC, Bullock R, Klunk WE, et al. 11C-PiB PET assessment of change in fibrillar amyloid-beta load in patients with Alzheimer's disease treated with bapineuzumab: a phase 2, doubleblind, placebo-controlled, ascending-dose study. Lancet Neurol. (2010) 9:36372. doi: 10.1016/S1474-4422(10)70043-0

70. Liu E, Schmidt ME, Margolin R, Sperling R, Koeppe R, Mason $\mathrm{NS}$, et al. Amyloid- $\beta$ 11C-PiB-PET imaging results from 2 randomized bapineuzumab phase 3 AD trials. Neurology. (2015) 85:692-700. doi: 10.1212/WNL.0000000000001877

71. Salloway S, Sperling R, Fox NC, Blennow K, Klunk W, Raskind M, et al. Two phase 3 trials of bapineuzumab in mild-to-moderate Alzheimer's disease. $N$ Engl J Med. (2014) 370:322-33. doi: 10.1056/NEJMoa1304839

72. Black RS, Sperling RA, Safirstein B, Motter RN, Pallay A, Nichols A, et al. A single ascending dose study of bapineuzumab in patients with Alzheimer disease. Alzheimer Dis Assoc Disord. (2010) 24:198203. doi: 10.1097/WAD.0b013e3181c53b00

73. Salloway S, Sperling R, Gilman S, Fox NC, Blennow K, Raskind $\mathrm{M}$, et al. A phase 2 multiple ascending dose trial of bapineuzumab in mild to moderate Alzheimer disease. Neurology. (2009) 73:206170. doi: 10.1212/WNL.0b013e3181c67808

74. Sperling R, Salloway S, Brooks DJ, Tampieri D, Barakos J, Fox NC, et al. Amyloid-related imaging abnormalities in patients with Alzheimer's disease treated with bapineuzumab: a retrospective analysis. Lancet Neurol. (2012) 11:241-9. doi: 10.1016/S1474-4422(12) 70015-7

75. Sevigny J, Chiao P, Bussière T, Weinreb PH, Williams L, Maier $\mathrm{M}$, et al. The antibody aducanumab reduces $A \beta$ plaques in Alzheimer's disease. Nature. (2016) 537:50-6. doi: 10.1038/nature 19323

76. Panza F, Solfrizzi V, Imbimbo BP, Giannini M, Santamato A, Seripa D, et al. Efficacy and safety studies of gantenerumab in patients with Alzheimer's disease. Expert Rev Neurother. (2014) 14:973-86. doi: 10.1586/14737175.2014. 945522

77. Ostrowitzki S, Lasser RA, Dorflinger E, Scheltens P, Barkhof F, Nikolcheva $\mathrm{T}$, et al. A phase III randomized trial of gantenerumab in prodromal
Alzheimer's disease. Alzheimers Res Ther. (2017) 9:95. doi: 10.1186/s13195017-0318-y

78. Carlson C, Siemers E, Hake A, Case M, Hayduk R, Suhy J, et al. Amyloidrelated imaging abnormalities from trials of solanezumab for Alzheimer's disease. Alzheimers Dement. (2016) 2:75-85. doi: 10.1016/j.dadm.2016.02.004

79. Adolfsson O, Pihlgren M, Toni N, Varisco Y, Buccarello AL, Antoniello K, et al. An effector-reduced anti- $\beta$-amyloid $(A \beta)$ antibody with unique a $\beta$ binding properties promotes neuroprotection and glial engulfment of A $\beta$. J Neurosci. (2012) 32:9677-89. doi: 10.1523/JNEUROSCI.4742-11.2012

80. Cummings JL, Cohen S, van Dyck CH, Brody M, Curtis C, Cho $\mathrm{W}$, et al. ABBY: A phase 2 randomized trial of crenezumab in mild to moderate Alzheimer disease. Neurology. (2018) 90:e1889-97. doi: 10.1212/WNL.0000000000005550

81. Salloway S, Honigberg LA, Cho W, Ward M, Friesenhahn M, Brunstein F, et al. Amyloid positron emission tomography and cerebrospinal fluid results from a crenezumab anti-amyloid-beta antibody double-blind, placebo-controlled, randomized phase II study in mild-to-moderate Alzheimer's disease (BLAZE). Alzheimers Res Ther. (2018) 10:96. doi: 10.1186/s13195-018-0424-5

82. Landen JW, Cohen S, Billing CB Jr, Cronenberger C, Styren S, Burstein AH, et al. Multiple-dose ponezumab for mild-to-moderate Alzheimer's disease: Safety and efficacy. Alzheimers Dement. (2017) 3:339-47. doi: 10.1016/j.trci.2017.04.003

83. Leurent C, Goodman JA, Zhang Y, He P, Polimeni JR, Gurol ME, et al Immunotherapy with ponezumab for probable cerebral amyloid angiopathy. Ann Clin Transl Neurol. (2019) 6:795-806. doi: 10.1002/acn3.761

84. Delnomdedieu M, Duvvuri S, Li DJ, Atassi N, Lu M, Brashear HR, et al. FirstIn-Human safety and long-term exposure data for AAB-003 (PF-05236812) and biomarkers after intravenous infusions of escalating doses in patients with mild to moderate Alzheimer's disease. Alzheimers Res Ther. (2016) 8:12. doi: $10.1186 / \mathrm{s} 13195-016-0177-y$

85. Logovinsky V, Satlin A, Lai R, Swanson C, Kaplow J, Osswald G et al Safety and tolerability of BAN2401-a clinical study in Alzheimer's disease with a protofibril selective $\mathrm{A} \beta$ antibody. Alzheimers Res Ther. (2016) 8:14. doi: 10.1186/s13195-016-0181-2

86. Cao Z, Lv J, Quan W. Low avidity and level of serum anti-A $\beta$ antibodies in patients with cerebral amyloid angiopathy-related cerebral hemorrhage. Int $J$ Neurosci. (2010) 120:760-4. doi: 10.3109/00207454.2010.520379

87. Piazza F, Greenberg SM, Savoiardo M, Gardinetti M, Chiapparini L, Raicher I, et al. Anti-amyloid $\beta$ autoantibodies in cerebral amyloid angiopathy-related inflammation: implications for amyloid-modifying therapies. Ann Neurol. (2013) 73:449-58. doi: 10.1002/ana.23857

88. DiFrancesco JC, Brioschi M, Brighina L, Ruffmann C, Saracchi E, Costantino G, et al. Anti-A $\beta$ autoantibodies in the CSF of a patient with CAA-related inflammation: a case report. Neurology. (2011) 76:8424. doi: 10.1212/WNL.0b013e31820e773c

89. Pfeifer M, Boncristiano S, Bondolfi L, Stalder A, Deller T, Staufenbiel M, et al. Cerebral hemorrhage after passive anti-Abeta immunotherapy. Science. (2002) 298:1379. doi: 10.1126/science.1078259

90. Thakker DR, Weatherspoon MR, Harrison J, Keene TE, Lane DS, Kaemmerer WF, et al. Intracerebroventricular amyloid-beta antibodies reduce cerebral amyloid angiopathy and associated micro-hemorrhages in aged $\mathrm{Tg} 2576$ mice. Proc Natl Acad Sci USA. (2009) 106:4501-6. doi: 10.1073/pnas.0813404106

91. Hall A, Pekkala T, Polvikoski T, van Gils M, Kivipelto M, Lötjönen $\mathrm{J}$, et al. Prediction models for dementia and neuropathology in the oldest old: the Vantaa 85+ cohort study. Alzheimers Res Ther. (2019) 11:11. doi: 10.1186/s13195-018-0450-3

Conflict of Interest Statement: The authors declare that the research was conducted in the absence of any commercial or financial relationships that could be construed as a potential conflict of interest.

Copyright $\odot 2019$ Chantran, Capron, Alamowitch and Aucouturier. This is an openaccess article distributed under the terms of the Creative Commons Attribution License (CC BY). The use, distribution or reproduction in other forums is permitted, provided the original author $(s)$ and the copyright owner(s) are credited and that the original publication in this journal is cited, in accordance with accepted academic practice. No use, distribution or reproduction is permitted which does not comply with these terms. 